\title{
Whooping Cough Causing Lower Motor Neuron Facial Palsy
}

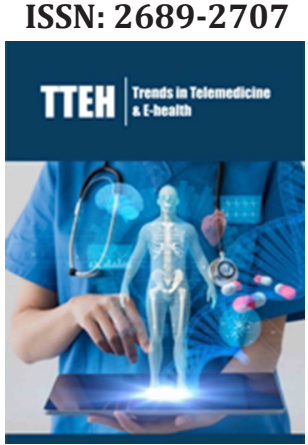

*Corresponding author: Sajid Ali Shah, Peads Department CMH Quetta, Pakistan

Submission: 㥁 March 20, 2019

Published: 想April 10, 2019

Volume 1 - Issue 4

How to cite this article: Sajid A S. Mucosal Whooping Cough Causing Lower Motor Neuron Facial Palsy. Trends Telemed E-Health. 1(4). TTEH. 000516. 2019. DOI: 10.31031/TTEH.2019.01.000516

Copyright@ Sajid Ali Shah, This article is distributed under the terms of the Creative Commons Attribution 4.0 International License, which permits unrestricted use and redistribution provided that the original author and source are credited.

\author{
Sajid Ali Shah* \\ Peads Department CMH Quetta, Pakistan
}

\begin{abstract}
A 5 years old child with pertussis reported to us with a unique complication not mentioned in the literature. He was thoroughly examined and investigated to find out cause for his lower motor neuron (LMN) facial palsy, but pertussis seemed to be the sole reason. With treatment of pertussis the patient showed marked improvement of neurological deficit.
\end{abstract}

Keywords: Whooping cough; Subconjunctival haemorrhages; Facial palsy; Lower motor neuron lesion

\section{Introduction}

Whooping cough is caused by gram negative bacteria Bordetella pertussis. Whooping cough is a vaccine preventable disease initially well controlled with whole cell vaccine but due to serious complications with this vaccine, it has now been replaced with acellular vaccine. Pertussis is a public health problem worldwide and despite effective vaccinations strategies it's still endemic in many parts of the world with frequent outbreaks occurring in many countries [1]. Some have blamed the new vaccines to be less effective than the older ones and other says that new sophisticated techniques for diagnosis are responsible for rise in the disease incidence [2].

Puresis is basically a non-inflammatory disease. There is no significant fever during the course of disease and the patient remains completely normal between the paroxysmal nonproductive cough episodes. These features make it unique from all other infectious respiratory disease. Infection can occur in all ages group as neither vaccine nor infection provide complete protection. Mortality is higher in female than male [3].

\section{Case Report}

A 5 years old male child reported to our outpatient department with history of cough for 17 days for which he took multiple medications in outdoor but no relief. The cough was in bouts and was so severed to developed bilateral redness of both eyes and used to follow by vomiting. For the last two days he was also unable to close his left eye and his angle of mouth used to deviates to right on smiling or talking. He was vaccinated as per expanded programme on immunization.

On examination a well looking, cooperative child with bilateral subconjunctival haemorrhages and wide-open left eye and stable vitals. On looking up there was absent frowning on left side of forehead and was unable to close his left eye. On showing teeth his mouth used to deviate to right. Rest of the general physical and systemic examination was unremarkable.

He was admitted and kept in isolation with advised of azithromycin and prednisolone according to body weight with base line investigations sent. He was also reviewed by ENT specialist and was having normal exam. During his stay in hospital he had low grade fever and used to play during bouts but during paroxysm used to have bursting exhaustive coughing followed by vomiting. His investigations revealed TLC 20,000/UL with 73\% lymphocytes while bleeding profile and rest of the investigations were with in normal limits. The patient was 
discharged on 7th day, advised to continue steroids, physiotherapy and follow up after one week. On follow up his neurological deficit has improved a lot and he was feeling much confident in facing me due to improved cosmetics as shown in Figure $1 \& 2$.
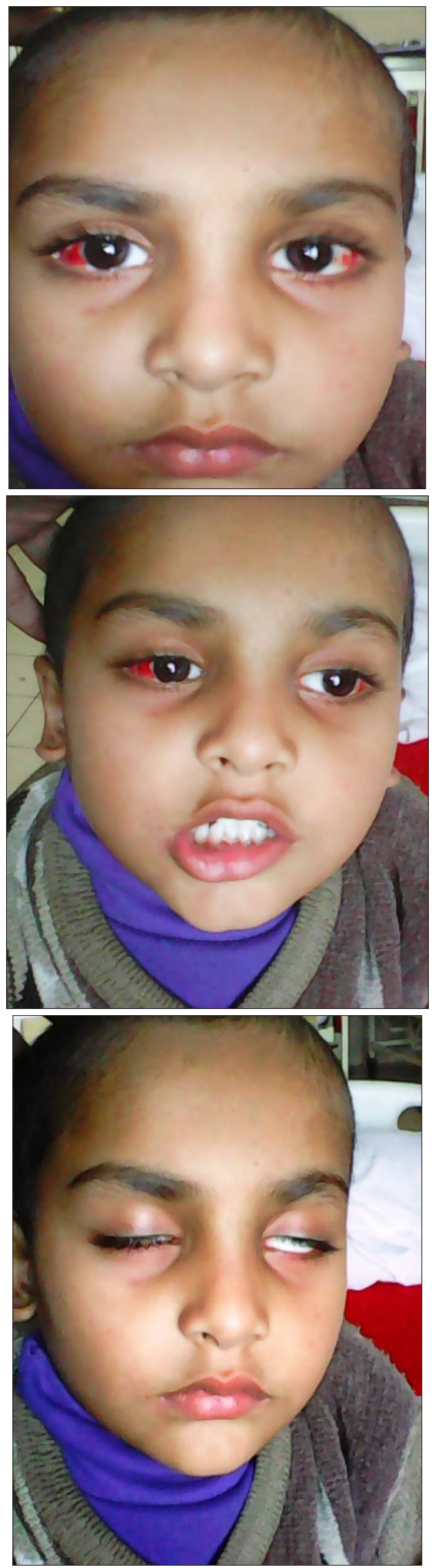

Figure 1: At time of presentations showing bilateral subconjunctival hemorrhages and signs of lower motor neuron facial palsy.
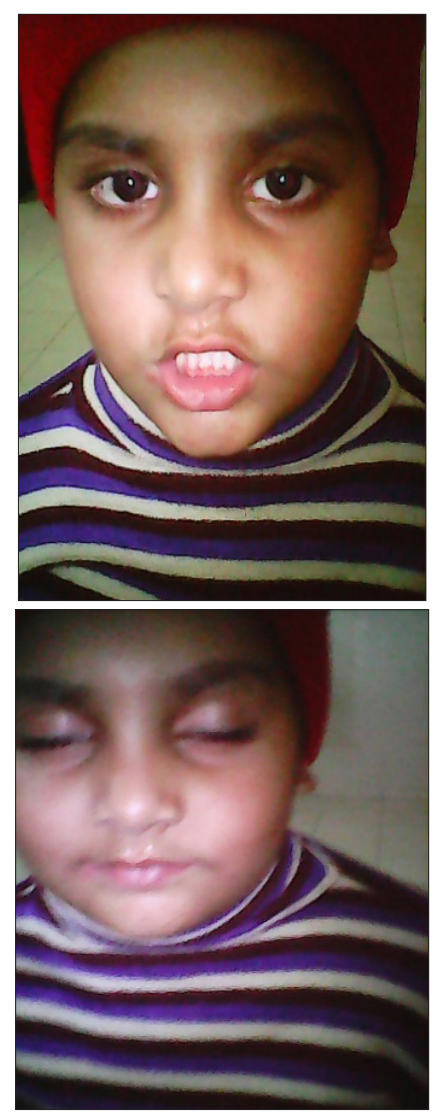

Figure 2: Taken about 3 weeks after presentation with improvement of neurological deficits.

\section{Discussion}

In a large group of in hospital pertussis patients 100\% were having cough for more than two weeks, post tussive vomiting were present in $77 \%$, paroxysm in $54 \%$ and $5 \%$ were vaccinated with 1 or more than one dose of pertussis vaccine [4]. In one series $23 \%$ of the pertussis patients had received 3 or more doses of pertussis vaccine. Complications mentioned in the literature include pneumonia, otitis, encephalitis, subconjunctival haemorrhages, seizures, malnutrition and dehydration. Post tussive vomiting, paroxysmal pattern of cough and well child between episodes points more towards pertussis as few diseases present in this manner $[5,6]$. Our patient was also vaccinated with all the abovementioned symptoms present. But unique in our patient was the development of lower motor neuron fascial palsy with whooping cough which has never been mentioned in the literature.

Pertussis diagnosis is confirmed if PCR/CULTURE positive, probable if clinical findings plus WBC changes are present. WBC changes include TLC more than 14,500 with more than $60 \%$ lymphocytes. Whooping cough if diagnosed solely on clinical basis is then tentative diagnosis [7]. In our case it was probable as no PCR/ CULTURE facilities available in Pakistan. In other parts of the world also pertussis diagnosis in made on clinical and epidemiological criteria and lab confirmation is not needed routinely $[6,8]$.

Mainstay of pertussis treatment is macrolides for 5 days which is as effective as long-term treatment with macrolides. Exchange 
transfusion, pertussis immunoglobulin and steroids should not be used routinely but may have a role in sever disease [5]. In our patient we used steroids as he was having LMN fascial palsy and it worked well.

\section{References}

1. Lima M, Estay SA, Fuentes R, Rubilar P, Broutin H, et al. (2015) Whooping cough dynamics in chile (1932-2010): disease temporal fluctuations across a north-south gradient. BMC infectious diseases 15: 590.

2. Robbins JB, Schneerson R, Kubler Kielb J, Keith JM, Trollfors B, et al. (2014) Toward a new vaccine for pertussis. Proceedings of the National Academy of Sciences 111(9): 3213-3216.

3. Cherry JD (2013) Pertussis: challenges today and for the future. PLoS Pathog 9(7): e1003418.
4. Stojanov S, Liese J, Belohradsky BH (2000) Hospitalization and complications in children under 2 years of age with Bordetella pertussis infection. Infection 28(2): 106-110.

5. Hartzell JD, Blaylock JM (2014) Whooping cough in 2014 and beyond: an update and review. CHEST Journal 146(1):205-214.

6. Guimarães LM, Carneiro EL, Carvalho Costa FA (2015) Increasing incidence of pertussis in brazil: a retrospective study using surveillance data. BMC Infect Dis 15: 442.

7. Herzig P, Hartmann C, Giani G, Fischer D, Von Kries R, et al. (1998) Pertussis complications in germany-3 years of hospital-based surveillance during the introduction of acellular vaccines. Infection 26(4): 227-231.

8. Gabutti G, Rota MC (2012) Pertussis: a review of disease epidemiology worldwide and in Italy. Int J Environ Res Public Health 9(12): 46264638. 